\title{
Assessment of the mechanical characteristics of the lower extremity muscles with myotonometric measurements in healthy individuals
}

\author{
DOI: https://doi.org/10.5114/pq.2020.97458
}

\section{Engin Ramazanoğlu, Serkan Usgu, Yavuz Yakut}

${ }^{1}$ Department of Physical Therapy and Rehabilitation, Faculty of Health Sciences, Hasan Kalyoncu University, Gaziantep, Turkey

\section{Abstract}

Introduction. This study aimed to establish normative values for stiffness, tone, and elasticity of lower extremity muscles and to determine age and sex differences.

Methods. Overall, 389 participants (199 females, 190 males) were included. The mechanical properties of the tibialis anterior (TA), rectus femoris (RF), vastus lateralis (VL), vastus medialis obliquus (VMO), gastrocnemius lateralis (GL), and gastrocnemius medialis (GM) muscles were assessed bilaterally with the MyotonPRO device. The data were compared with respect to sex and age. Results. The mechanical properties were significantly higher bilaterally in males than females in all parameters $(p<0.05)$. Right TA stiffness and elasticity, GM tone and stiffness were higher than left in females $(p<0.05)$. Greater VMO elasticity and RF tone were found in left vs. right $(p<0.05)$. Right GL-VL stiffness and elasticity were greater than left in males $(p<0.05)$. VMO-RF tones were bigger in left compared with right $(p<0.05)$. Among age groups, right-left TA tone and stiffness were greater in group 1 (18-28 years old) $(p<0.05)$. Right-left VL-VMO tones, and left RF stiffness and tone were lower in group 2 (29-39 years old) $(p<0.05)$. Right GM-VMO stiffness, right-left TA-GL-GM-VMO and RF elasticity were greater in group 3 (40-50 years old) compared with others $(p<0.05)$.

Conclusions. The mechanical properties of leg muscles were bilaterally higher in males. Different characteristics were observed of different muscles for both sexes. GL-GM-VMO-RF elasticity decreased, and TA stiffness and VMO tone increased with advancing age in both legs.

Key words: muscle tone, viscoelastic properties, age factors

\section{Introduction}

Skeletal muscles have complex features and functions. With aging, significant changes occur in the function and physiology of the muscles [1]. Age-related structural and biochemical changes in the cellular and extracellular matrix include muscle fibre redistribution, altered protein concentration, changes in cross-bridges, and degeneration [1-3]. This age-related process called sarcopenia is associated with reduced muscle mass and strength. While females have less muscle mass and strength than males, they have higher endurance. This difference in functional capacity is actually a result of the loss of type II (fast twitching) muscle fibres, particularly in the peripheral areas. Aging has no impact on type I (slow twitching) muscle fibres.

Physiological changes in the muscle affect its mechanical properties such as tone, elasticity, stiffness, causing reduced elasticity and increased stiffness of the muscle $[4,5]$. It is important to evaluate the changes in the mechanical properties of the muscles, which can limit physical performance and impair quality of life. It is difficult to objectively distinguish whether any changes in the muscle tone or its mechanical properties are due to aging or a result of neurodegenerative disorders [6].

Technological devices are used for the assessment of the mechanical properties of the musculoskeletal system. Electromyography (EMG) is one of the best known and commonly used methods to evaluate muscle functions objectively. Total muscle activity can be determined by using surface (skin) or needle (inserted into the muscle) electrodes. The isolated muscle activity can only be recorded with an EMG device which involves an invasive and painful procedure [7, 8]. Other modalities such as elastography, shear wave ultrasound elastography, or free oscillation techniques are valid and reliable tools for quantifying the mechanical properties of muscles and tendons. However, access to these systems is not always possible or may be limited in clinics because of high purchasing and maintenance costs and the requirement of technical expertise [9]. Thus, there is a need for objective, cost-effective, reliable, valid, and easy-to-use methods to evaluate the mechanical properties of the musculoskeletal system [9, 10]. More recently, a new hand-held device known as MyotonPRO (Müomeetria Ltd., Tallinn, Estonia) was introduced. MyotonPRO offers a non-invasive, cost-effective, and quantitative method to measure the mechanical properties of the musculoskeletal system [11, 12]. This portable, feasible, and userfriendly device has shown good to excellent reliability in healthy individuals [11, 13], athletes [14], elderly [15], cancer and stroke patients [16-18], and patients with neurodegenerative disease [19]. The objective measurement of soft tissue stiffness, tone, and elasticity provided by MyotonPRO has high test-retest reliability and repeatability [9, 20-22]. MyotoPRO may be used as a tool for quick assessment of soft tissue properties, as well as a convenient diagnostic and monitoring device in small-volume clinics and research laboratories [23-26]. There are many studies that investigated age- and sex-related changes in the mechanical properties of the musculoskeletal system reporting variable results $[27,28]$.

The purpose of this study was to establish normative data for stiffness, tone, and elasticity of the lower extremity muscles

Correspondence address: Serkan Usgu, Hasan Kalyoncu Üniversitesi, Sağlık Bilimleri Fakültesi, Fizyoterapi ve Rehabilitasyon Bölümü, Havaalanı Yolu Üzeri 8. km, 27410, Gaziantep, Turkey, e-mail: serkan.usgu@hku.edu.tr 
and to determine age and sex differences in a healthy population. It was hypothesized that advanced age would increase muscle stiffness and tone and decrease muscle elasticity.

\section{Subjects and methods}

\section{Participants}

A total of 390 healthy individuals with an age range of 18-50 years (mean age: $28.64 \pm 9.68$ years), including 200 females (mean age: $29.92 \pm 9.63$ years) and 190 males (mean age: $27.29 \pm 9.57$ years) were involved in the study. A power analysis was performed to estimate the sample size on the basis of the confidence interval of the mean. The MedCalc software, version 18.11.3, was used for statistical analyses [29]. Healthy individuals with current systemic or metabolic diseases, a history of psychiatric illness or drug abuse, any conditions associated with muscle disorders or muscle atrophy, or a recent (within the previous 3 months) surgery involving the musculoskeletal system were excluded from the study.

One individual was excluded from the study because of a recent surgical operation, which resulted in a total sample of 389 subjects. The participants were divided into 3 different subcategories by sex (male and female), leg dominance (right and left leg dominant), and age.

The age range of the subgroups was as follows: group 1: 18-28 years $(n=235)$, group 2: $29-39$ years $(n=85)$, and group 3: $40-50$ years $(n=69)$. Among the 190 male participants, 131 (55.7\%) were in group 1, 29 (34.1\%) in group 2, and $30(43.5 \%)$ in group 3 . Among the 199 female participants, 104 (44.3\%) were in group 1, $56(65.9 \%)$ in group 2, and $39(56.5 \%)$ in group 3.

The study was conducted in Hasan Kalyoncu University, Faculty of Health Sciences. The nature and purpose of the study was explained to the participants.

\section{Method}

The physical characteristics and demographic data of the participants were recorded before myotonometric mea- surements. The dominant leg was determined as the one used for kicking a ball. Muscle tone, stiffness, and elasticity were measured bilaterally for the specific muscles in the lower extremity (Table 1) (Figure 1). The mean value of 3 consecutive measurements was recorded as the final value. A MyotonPRO device (Müomeetria Ltd., Tallinn, Estonia) was used for the assessment of muscle tone, elasticity, and stiffness. The device provides data about these 3 mechanical features of any muscle: (1) tone [f]; oscillation frequency $(\mathrm{Hz})$ refers to the passive or resting tone (intrinsic tension) of a muscle without any voluntary contraction [12]; (2) stiffness [S]; stiffness $(\mathrm{N} / \mathrm{m})$ is a biomechanical feature of a muscle that characterizes its resistance to a contraction or an external force that disrupts its initial state [12]; (3) elasticity [D]; elasticity is measured as a logarithmic reduction of the natural oscillations in a tissue. Elasticity is a biomechanical feature that characterizes the ability of a tissue to restore its initial state after a contraction or an impact of an external force. It describes the diffusion of mechanical energy within the oscillation cycle [12].

When placed vertically on the muscle, a probe (3- $\mathrm{mm}$ diameter) creates constant pre-excitations $(0.18 \mathrm{~N})$ and generates short-term (15 ms), low-force $(0.4 \mathrm{~N})$ mechanical stimu-

Table 1. The measurement reference points of muscles

\begin{tabular}{|c|c|}
\hline Muscles & Reference points \\
\hline Rectus femoris (RF) & $\begin{array}{c}2 / 3 \text { of the anterior superior iliac spine } \\
\text { and patella [6] }\end{array}$ \\
\hline Vastus lateralis (VL) & $25 \mathrm{~cm}$ below the trochanter major \\
\hline $\begin{array}{l}\text { Vastus medialis } \\
\text { obliquus (VMO) }\end{array}$ & $\begin{array}{l}18 \mathrm{~cm} \text { above the medial edge } \\
\text { of the midpoint of patella }\end{array}$ \\
\hline Tibialis anterior (TA) & $12 \mathrm{~cm}$ below the lateral condyle of femur \\
\hline $\begin{array}{l}\text { Gastrocnemius } \\
\text { lateralis (GL) }\end{array}$ & $\begin{array}{l}30 \mathrm{~cm} \text { above the posterior edge } \\
\text { of the lateral malleolus }\end{array}$ \\
\hline $\begin{array}{l}\text { Gastrocnemius } \\
\text { medialis (GM) }\end{array}$ & $\begin{array}{l}30 \mathrm{~cm} \text { above the posterior edge } \\
\text { of the medial malleolus }\end{array}$ \\
\hline
\end{tabular}

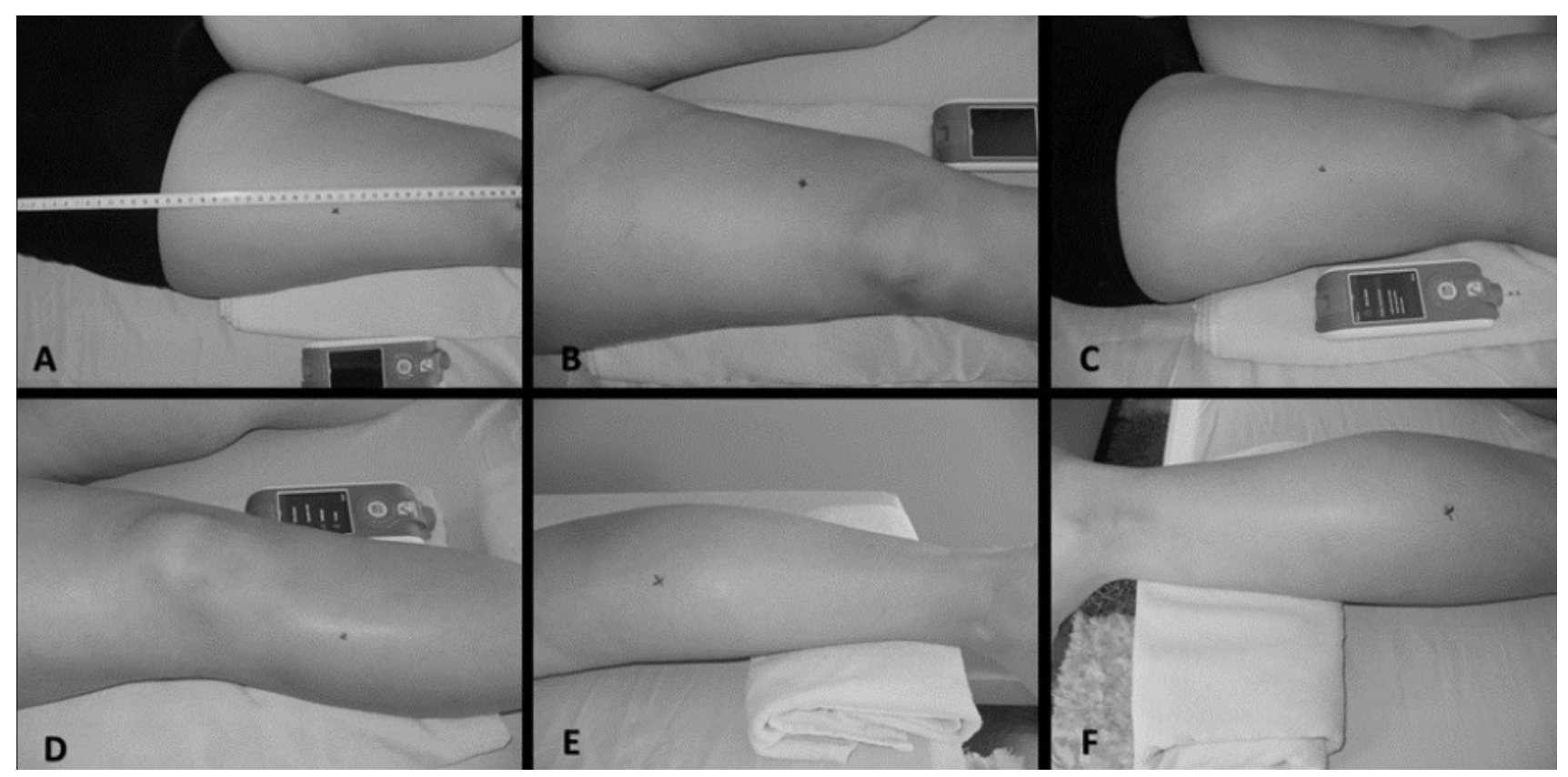

Figure 1. The reference points of muscles for myotonometric assessment: (A) rectus femoris, (B) vastus medialis obliques, $(C)$ vastus lateralis, $(D)$ tibialis anterior, $(E)$ gastrocnemius medialis, $(F)$ gastrocnemius lateralis 


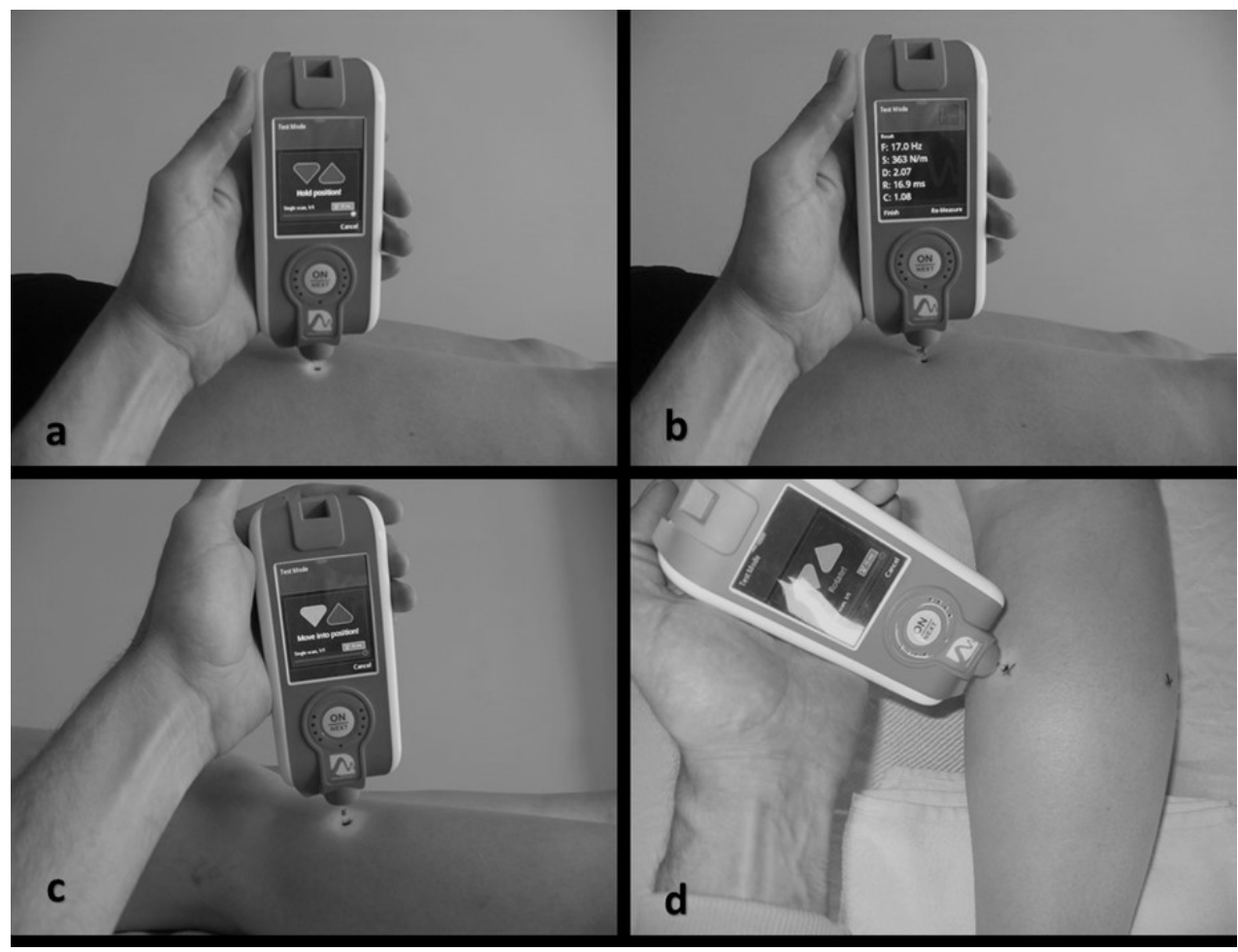

Figure 2. Examples

of myotonometric assessment:

$(a, b)$ rectus femoris

(c) tibialis anterior

(d) gastrocnemius lateralis

lations. These stimulations induce damped natural oscillations in the tissue and the device records these oscillations with an accelerometer. Muscle tone, elasticity, and stiffness are calculated separately by the device [30].

\section{Reference points for myotonic measurement}

The measurements were obtained from the assumed reference points of the muscles in supine and prone positions (Table 1, Figure 2). Study legs were randomly measured for each participant, i.e. no criteria were applied for starting measurements at the right or left leg. The arithmetic mean of 3 consecutive measurements was recorded as the final value.

The participants were asked to either drive or use public transportation to come to the laboratory for the measurements and avoid intense activities that could affect the muscles, such as cycling, running, or brisk walking.

\section{Statistical analysis}

Descriptive statistics were summarized as mean \pm standard deviation for numerical data. The Shapiro-Wilk test was used to check whether the data were normally distributed. For non-normally distributed data, the Mann-Whitney $U$ test was applied to compare the differences between males and females (sex), and right and left legs (leg dominance). In addition, all individuals were subcategorized by age. When 3 or more groups were considered (e.g. in the case of analysis by age), the Kruskal-Wallis test served to compare non-normally distributed variables. If Kruskal-Wallis test yielded a significant $p$ value, post-hoc pairwise comparisons (after Dunn correction) were used to determine the source of the difference. In addition, the Spearman rank correlation test established correlations between numerical variables. The magnitude of the correlations was interpreted as follows: below 0.499 : poor, 0.500-0.699: moderate, 0.700-0.899: good, and 0.9001.000: excellent [31]. The SPSS software (Windows version 24) was used for statistical analyses and a $p$ value less than 0.05 was considered statistically significant.

\section{Ethical approval}

The research related to human use has complied with all the relevant national regulations and institutional policies, has followed the tenets of the Declaration of Helsinki, and has been approved by the Ethics Committee for Non-Interventional Research of the Faculty of Health Sciences, Hasan Kalyoncu University, on 06.06.2018 (No. 2018-05).

\section{Informed consent}

Informed consent has been obtained from all individuals included in this study.

\section{Results}

The descriptive statistics of age, height, body weight, and body mass index (BMI) with respect to sex are shown in Table 2. Females were older than males $(p=0.002)$; however, males were taller $(p=0.001)$ and heavier $(p=0.001)$ than females. Males and females had similar BMI values $(p=0.408)$.

\section{Comparison of the mechanical properties} of lower extremity muscles in all individuals

The tone and elasticity of tibialis anterior (TA) were greater in the right legs vs. the left legs $(p=0.024, p=0.043$, respectively). Gastrocnemius lateralis (GL) stiffness was greater in the left legs than in the right legs $(p=0.003)$. Gastrocnemius medialis (GM) tone was greater in the left legs than in the right legs $(p=0.010)$. Vastus lateralis $(V L)$ elasticity was greater in the right legs vs. the left legs $(p=0.003)$. Vastus medialis obliquus (VMO) elasticity was greater in the left legs vs. the right legs $(p=0.001)$. Left legs showed greater rectus femoris (RF) tone than the right legs $(p=0.010)$. RF elasticity of the right legs was greater than of the left legs $(p=$ 0.047). No statistically significant difference was observed for the remaining parameters $(p>0.05)$ (Table 3$)$. 
Table 2. Demographic characteristics of participants

\begin{tabular}{|c|c|c|c|c|c|}
\hline Parameter & $\begin{array}{c}\text { All individuals }(n=389) \\
(\text { mean } \pm S D)\end{array}$ & $\begin{array}{l}\text { Males }(n=190) \\
\quad(\text { mean } \pm S D)\end{array}$ & $\begin{array}{c}\text { Females }(n=199) \\
(\text { mean } \pm S D)\end{array}$ & $z$ & $p$ \\
\hline Age (year) & $28.64 \pm 9.68$ & $27.29 \pm 9.57$ & $29.92 \pm 9.63$ & -3.064 & 0.002 \\
\hline Height (m) & $1.69 \pm 0.86$ & $1.75 \pm 0.07$ & $1.64 \pm 0.06$ & -13.614 & 0.001 \\
\hline Body weight (kg) & $71.91 \pm 14.42$ & $76.11 \pm 13.98$ & $67.9 \pm 13.72$ & -5.399 & 0.001 \\
\hline BMI $\left(\mathrm{kg} / \mathrm{m}^{2}\right)$ & $25.14 \pm 4.58$ & $24.87 \pm 4.06$ & $25.40 \pm 5.02$ & -0.827 & 0.408 \\
\hline
\end{tabular}

$\mathrm{BMI}$ - body mass index. Bold denotes statistically significant values.

Table 3. Comparison of the mechanical properties of lower extremity muscles in all individuals

\begin{tabular}{|c|c|c|c|c|}
\hline \multirow{2}{*}{ Parameter } & \multicolumn{4}{|c|}{ All participants $(n=389)$} \\
\hline & Right (mean $\pm S D$ ) & Left (mean $\pm S D$ ) & $z$ & $p$ \\
\hline TA tone $(\mathrm{Hz})$ & $18.5 \pm 3.38$ & $18.27 \pm 3.32$ & -2.256 & 0.024 \\
\hline TA stiffness (N/m) & $365.27 \pm 85.03$ & $360.57 \pm 80.5$ & -1.603 & 0.109 \\
\hline TA elasticity (log) & $1.13 \pm 0.32$ & $1.1 \pm 0.32$ & -2.023 & 0.043 \\
\hline $\mathrm{GL}$ tone $(\mathrm{Hz})$ & $15.34 \pm 1.75$ & $15.44 \pm 1.92$ & -1.776 & 0.076 \\
\hline GL stiffness (N/m) & $267.68 \pm 37.84$ & $274.35 \pm 53.33$ & -3.023 & 0.003 \\
\hline GL elasticity (log) & $1.18 \pm 0.27$ & $1.21 \pm 0.26$ & -1.886 & 0.059 \\
\hline GM tone $(\mathrm{Hz})$ & $15.17 \pm 1.9$ & $15.02 \pm 1.89$ & -2.572 & 0.010 \\
\hline GM stiffness (N/m) & $256.29 \pm 35.53$ & $254.24 \pm 37.07$ & -1.095 & 0.273 \\
\hline GM elasticity (log) & $1.32 \pm 0.29$ & $1.3 \pm 0.3$ & -1.418 & 0.156 \\
\hline VL tone $(\mathrm{Hz})$ & $15.1 \pm 2.67$ & $15.02 \pm 2.66$ & -0.765 & 0.444 \\
\hline VL stiffness (N/m) & $260.1 \pm 61.31$ & $258.17 \pm 62.05$ & -0.824 & 0.410 \\
\hline VL elasticity (log) & $1.25 \pm 0.34$ & $1.21 \pm 0.33$ & -2.994 & 0.003 \\
\hline VMO tone $(\mathrm{Hz})$ & $12.87 \pm 1.74$ & $13.07 \pm 2.37$ & -1.717 & 0.086 \\
\hline VMO stiffness (N/m) & $202.51 \pm 40.3$ & $205.71 \pm 45.22$ & -1.652 & 0.099 \\
\hline VMO elasticity (log) & $1.16 \pm 0.33$ & $1.22 \pm 0.37$ & -3.779 & 0.001 \\
\hline $\mathrm{RF}$ tone $(\mathrm{Hz})$ & $14.11 \pm 1.78$ & $14.27 \pm 1.74$ & -2.559 & 0.010 \\
\hline RF stiffness (N/m) & $233.33 \pm 41.08$ & $236.05 \pm 45.71$ & -1.304 & 0.192 \\
\hline RF elasticity (log) & $1.16 \pm 0.31$ & $1.13 \pm 0.28$ & -1.983 & 0.047 \\
\hline
\end{tabular}

TA - tibialis anterior, GL - gastrocnemius lateralis, GM - gastrocnemius medialis, VL - vastus lateralis, VMO - vastus medialis obliquus, $\mathrm{RF}$ - rectus femoris

Bold denotes statistically significant values.

Comparison of the mechanical properties of lower extremity muscles depending on leg dominance

The comparison of right and left lower extremity muscles according to leg dominance revealed no significant differences in the mechanical properties in the participants with left or right leg dominance $(p>0.05)$ (Table 4).

Comparison of the mechanical properties of lower extremity muscles depending on sex

The comparison of right and left lower extremity muscles according to sex revealed greater values in males for all of the mechanical properties $(p<0.05)$ (Table 5).

Comparison of the mechanical properties of lower extremity muscles in male and female groups separately

In males, left legs showed greater GL stiffness and elasticity than the right legs ( $p=0.001, p=0.015$, respectively). VL elasticity was greater in the right legs vs. the left legs $(p=0.002)$. VMO tone and elasticity were greater in the left legs than in the right legs ( $p=0.002, p=0.006$, respectively). No significant differences were found for other parameters $(p>0.05)$.

In females, right leg TA stiffness and elasticity were greater vs. the left leg ( $p=0.017, p=0.020$, respectively). GM tone and stiffness were greater in the right legs than in the left legs ( $p=0.030, p=0.039$, respectively). VMO elasticity and RF tone of the left legs were greater vs. the right legs $(p=0.008$, $p=0.006$, respectively). Other parameters did not show a statistically significant difference $(p>0.05)$ (Table 6).

Comparison of the mechanical properties of lower extremity muscles depending on age

When data were compared between age groups (males and females combined to eliminate sex effect), the post-hoc analysis showed significantly greater right-left TA muscle tone and stiffness in group 1 than in group 2 (right side, $p=0.000$, $p=0.000$; left side, $p=0.007, p=0.007$, respectively). No significant differences were found between group 2 vs. group 3 
Table 4. Comparison of the mechanical properties of lower extremity muscles depending on leg dominance

\begin{tabular}{|c|c|c|c|c|}
\hline Parameter & $\begin{array}{l}\text { Right }(n=366) \\
(\text { mean } \pm S D)\end{array}$ & $\begin{array}{l}\text { Left }(n=23) \\
(\text { mean } \pm S D)\end{array}$ & $z$ & $p$ \\
\hline Right TA tone (Hz) & $18.47 \pm 3.37$ & $19.02 \pm 3.68$ & -0.543 & 0.587 \\
\hline Right TA stiffness (N/m) & $364.44 \pm 84.82$ & $378.48 \pm 89.19$ & -0.569 & 0.570 \\
\hline Right TA elasticity (log) & $1.13 \pm 0.32$ & $1.1 \pm 0.3$ & -0.350 & 0.726 \\
\hline Left TA tone $(\mathrm{Hz})$ & $18.25 \pm 3.32$ & $18.63 \pm 3.44$ & -0.561 & 0.575 \\
\hline Left TA stiffness (N/m) & $359.93 \pm 80.52$ & $370.83 \pm 81.18$ & -0.591 & 0.555 \\
\hline Left TA elasticity (log) & $1.1 \pm 0.32$ & $1.1 \pm 0.24$ & -0.322 & 0.747 \\
\hline Right GL tone (Hz) & $15.34 \pm 1.76$ & $15.27 \pm 1.59$ & -0.027 & 0.979 \\
\hline Right GL stiffness (N/m) & $267.55 \pm 38.26$ & $269.7 \pm 30.99$ & -0.241 & 0.810 \\
\hline Right GL elasticity (log) & $1.18 \pm 0.27$ & $1.21 \pm 0.25$ & -0.786 & 0.432 \\
\hline Left GL tone $(\mathrm{Hz})$ & $15.42 \pm 1.91$ & $15.76 \pm 2.01$ & -0.969 & 0.332 \\
\hline Left GL stiffness (N/m) & $272.56 \pm 42.3$ & $302.74 \pm 39.88$ & -0.489 & 0.625 \\
\hline Left GL elasticity (log) & $1.21 \pm 0.26$ & $1.24 \pm 0.24$ & -1.040 & 0.298 \\
\hline Right GM tone (Hz) & $15.16 \pm 1.9$ & $15.34 \pm 1.84$ & -0.466 & 0.641 \\
\hline Right GM stiffness (N/m) & $256.12 \pm 35.4$ & $259.04 \pm 38.27$ & -0.107 & 0.915 \\
\hline Right GM elasticity (log) & $1.32 \pm 0.29$ & $1.33 \pm 0.22$ & -0.546 & 0.585 \\
\hline Left GM tone (Hz) & $15 \pm 1.89$ & $15.5 \pm 1.91$ & -1.124 & 0.261 \\
\hline Left GM stiffness (N/m) & $253.52 \pm 36.67$ & $265.57 \pm 42.14$ & -1.184 & 0.237 \\
\hline Left GM elasticity (log) & $1.3 \pm 0.3$ & $1.3 \pm 0.31$ & -0.113 & 0.910 \\
\hline Right VL tone $(\mathrm{Hz})$ & $15.12 \pm 2.7$ & $14.68 \pm 1.98$ & -0.594 & 0.553 \\
\hline Right VL stiffness (N/m) & $260.5 \pm 62.08$ & $253.7 \pm 47.92$ & -0.440 & 0.660 \\
\hline Right VL elasticity (log) & $1.25 \pm 0.34$ & $1.26 \pm 0.38$ & -0.032 & 0.975 \\
\hline Left VL tone $(\mathrm{Hz})$ & $15 \pm 2.67$ & $15.3 \pm 2.46$ & -0.516 & 0.606 \\
\hline Left VL stiffness (N/m) & $257.42 \pm 62.43$ & $270.17 \pm 55.56$ & -1.158 & 0.247 \\
\hline Left VL elasticity (log) & $1.21 \pm 0.33$ & $1.26 \pm 0.31$ & -0.944 & 0.345 \\
\hline Right VMO tone $(\mathrm{Hz})$ & $12.89 \pm 1.75$ & $12.57 \pm 1.63$ & -0.750 & 0.453 \\
\hline Right VMO stiffness (N/m) & $202.26 \pm 40.26$ & $206.52 \pm 41.62$ & -0.187 & 0.851 \\
\hline Right VMO elasticity (log) & $1.16 \pm 0.33$ & $1.25 \pm 0.34$ & -1.069 & 0.285 \\
\hline Left VMO tone $(\mathrm{Hz})$ & $13.11 \pm 2.41$ & $12.48 \pm 1.37$ & -1.034 & 0.301 \\
\hline Left VMO stiffness (N/m) & $205.91 \pm 45.89$ & $202.48 \pm 33.47$ & -0.078 & 0.938 \\
\hline Left VMO elasticity (log) & $1.22 \pm 0.37$ & $1.27 \pm 0.38$ & -0.397 & 0.692 \\
\hline Right RF tone (Hz) & $14.12 \pm 1.79$ & $13.97 \pm 1.53$ & -0.440 & 0.660 \\
\hline Right RF stiffness (N/m) & $233.55 \pm 41.26$ & $229.74 \pm 38.89$ & -0.748 & 0.455 \\
\hline Right RF elasticity (log) & $1.15 \pm 0.31$ & $1.21 \pm 0.35$ & -0.803 & 0.422 \\
\hline Left RF tone $(\mathrm{Hz})$ & $14.26 \pm 1.76$ & $14.42 \pm 1.4$ & -0.549 & 0.583 \\
\hline Left RF stiffness (N/m) & $234.6 \pm 41.89$ & $259.09 \pm 84.57$ & -1.208 & 0.227 \\
\hline Left RF elasticity (log) & $1.13 \pm 0.28$ & $1.21 \pm 0.33$ & -1.222 & 0.222 \\
\hline
\end{tabular}

TA - tibialis anterior, GL - gastrocnemius lateralis, GM - gastrocnemius medialis, VL - vastus lateralis, VMO - vastus medialis obliquus, $\mathrm{RF}$ - rectus femoris

and between group $1 \mathrm{vs.} \mathrm{group} 3(p>0.05)$. While right GM muscle stiffness was significantly greater in group 3 vs. group 2 ( $p=0.012$ ), no significant differences were found between group 1 vs. group 2 and between group 1 vs. group 3 $(p>0.05)$. Right-left VL and VMO muscle tones were significantly greater in group 1 vs. group 2 (right side, $p=0.009$, $p=0.004$; left side, $p=0.003, p=0.002$, respectively), with no significant differences between group 1 vs. group 3 and between group 2 vs. group $3(p>0.05)$. Left RF muscle tones of groups 1 and 3 were significantly greater vs. group 2 ( $p=$ $0.007, p=0.009$, respectively) and no significant difference was found between group 1 and group $3(p>0.05)$. Although left RF muscle stiffness of group 3 was significantly greater vs. group $2(p=0.005)$, no significant differences were found 
Table 5. Comparison of the mechanical properties of lower extremity muscles depending on sex

\begin{tabular}{|c|c|c|c|c|c|c|c|c|}
\hline \multirow[b]{2}{*}{ Parameter } & \multicolumn{4}{|c|}{ Right } & \multicolumn{4}{|c|}{ Left } \\
\hline & $\begin{array}{c}\text { Males } \\
(n=190) \\
(\text { mean } \pm S D)\end{array}$ & $\begin{array}{c}\text { Females } \\
(n=199) \\
(\text { mean } \pm S D)\end{array}$ & $z$ & $p$ & $\begin{array}{c}\text { Males } \\
(n=190) \\
(\text { mean } \pm S D)\end{array}$ & $\begin{array}{c}\text { Females } \\
(n=199) \\
(\text { mean } \pm S D)\end{array}$ & $z$ & $p$ \\
\hline TA tone $(\mathrm{Hz})$ & $20.95 \pm 2.66$ & $16.16 \pm 2.1$ & -14.525 & 0.001 & $20.63 \pm 2.65$ & $16.02 \pm 2.11$ & -14.468 & 0.001 \\
\hline TA stiffness (N/m) & $405.65 \pm 74.17$ & $326.72 \pm 76.54$ & -10.222 & 0.001 & $403.59 \pm 63.66$ & $319.49 \pm 73.19$ & -11.114 & 0.001 \\
\hline TA elasticity (log) & $1.2 \pm 0.38$ & $1.06 \pm 0.23$ & -3.663 & 0.001 & $1.18 \pm 0.38$ & $1.03 \pm 0.22$ & -3.736 & 0.001 \\
\hline $\mathrm{GL}$ tone $(\mathrm{Hz})$ & $16.18 \pm 1.54$ & $14.53 \pm 1.55$ & -9.659 & 0.001 & $16.34 \pm 1.78$ & $14.58 \pm 1.64$ & -9.184 & 0.001 \\
\hline GL stiffness (N/m) & $279.38 \pm 35.56$ & $256.5 \pm 36.62$ & -5.803 & 0.001 & $290.86 \pm 60.82$ & $258.58 \pm 39.12$ & -6.739 & 0.001 \\
\hline GL elasticity (log) & $1.24 \pm 0.29$ & $1.13 \pm 0.24$ & -3.322 & 0.001 & $1.29 \pm 0.29$ & $1.13 \pm 0.2$ & -5.781 & 0.001 \\
\hline GM tone $(\mathrm{Hz})$ & $16.22 \pm 1.74$ & $14.18 \pm 1.46$ & -11.056 & 0.001 & $16.07 \pm 1.59$ & $14.03 \pm 1.6$ & -11.198 & 0.001 \\
\hline GM stiffness (N/m) & $269.05 \pm 33.85$ & $244.11 \pm 32.78$ & -7.484 & 0.001 & $269.46 \pm 34.2$ & $239.7 \pm 33.78$ & -8.577 & 0.001 \\
\hline GM elasticity (log) & $1.41 \pm 0.3$ & $1.24 \pm 0.24$ & -5.473 & 0.001 & $1.39 \pm 0.32$ & $1.22 \pm 0.26$ & -5.376 & 0.001 \\
\hline VL tone $(\mathrm{Hz})$ & $16.94 \pm 2.01$ & $13.33 \pm 1.91$ & -14.190 & 0.001 & $16.87 \pm 2$ & $13.25 \pm 1.89$ & -14.160 & 0.001 \\
\hline VL stiffness (N/m) & $298.66 \pm 47.58$ & $223.29 \pm 49.15$ & -13.281 & 0.001 & $297.52 \pm 46.69$ & $220.61 \pm 50.59$ & -13.643 & 0.001 \\
\hline VL elasticity (log) & $1.43 \pm 0.32$ & $1.08 \pm 0.27$ & -10.304 & 0.001 & $1.36 \pm 0.3$ & $1.06 \pm 0.29$ & -9.702 & 0.001 \\
\hline VMO tone $(\mathrm{Hz})$ & $13.86 \pm 1.58$ & $11.93 \pm 1.31$ & -11.720 & 0.001 & $14.37 \pm 2.5$ & $11.83 \pm 1.36$ & -12.846 & 0.001 \\
\hline VMO stiffness (N/m) & $225.89 \pm 37.6$ & $180.2 \pm 28.42$ & -11.667 & 0.001 & $229.59 \pm 44.4$ & $182.9 \pm 32.49$ & -10.695 & 0.001 \\
\hline VMO elasticity (log) & $1.26 \pm 0.29$ & $1.07 \pm 0.35$ & -7.099 & 0.001 & $1.34 \pm 0.37$ & $1.12 \pm 0.34$ & -6.819 & 0.001 \\
\hline RF tone $(\mathrm{Hz})$ & $14.83 \pm 1.38$ & $13.42 \pm 1.85$ & -8.374 & 0.001 & $14.91 \pm 1.4$ & $13.65 \pm 1.81$ & -8.046 & 0.001 \\
\hline RF stiffness (N/m) & $252.6 \pm 32.62$ & $214.93 \pm 39.94$ & -9.577 & 0.001 & $255.62 \pm 43$ & $217.37 \pm 40.14$ & -9.130 & 0.001 \\
\hline RF elasticity (log) & $1.28 \pm 0.29$ & $1.04 \pm 0.28$ & -7.889 & 0.001 & $1.25 \pm 0.26$ & $1.02 \pm 0.26$ & -8.479 & 0.001 \\
\hline
\end{tabular}

$\mathrm{TA}$ - tibialis anterior, GL - gastrocnemius lateralis, GM - gastrocnemius medialis, VL - vastus lateralis, VMO - vastus medialis obliquus, $\mathrm{RF}$ - rectus femoris

Bold denotes statistically significant values.

between group 1 vs. group 2 and between group 1 vs. group 3 $(p>0.05)$.

Group 3 showed significantly greater muscle elasticity of the right-left TA, GL, GM (group 1, right side, $p=0.001, p=$ $0.001, p=0.001$; left side, $p=0.001, p=0.001, p=0.001$; group 2, right side, $p=0.000, p=0.002, p=0.007$; left side, $p=0.001, p=0.007, p=0.011$, respectively), right VMO (group 1, $p=0.000$; group 2, $p=0.003$ ), and left RF (group 1, $p=0.001$; group $2, p=0.029$ ) in comparison with other age groups. No significant difference was found between group 1 and group $2(p>0.05)$. Right RF muscle elasticity of group 3 was significantly higher vs. group $2(p=0.001)$ but there were no significant differences between group 1 vs. group 2 or between group 1 vs. group 3 ( $p>0.05$ ). Left VMO muscle elasticity of groups 2 and 3 were significantly greater than in group 1 $(p=0.039, p=0.000$, respectively), with no significant difference between group 2 and group $3(p>0.05)$. The comparison of mechanical properties among age groups is shown in Table 7.

A poor positive correlation was found between right-left $\mathrm{GL}$ elasticity and age $(r=0.229, p=0.001 ; r=0.194, p=0.001$, respectively). A poor positive correlation was observed between right-left GM elasticity and age $(r=0.157, p=0.002$; $r=0.133, p=0.001$, respectively). A poor negative correlation was detected between right $\mathrm{VL}$ tone and age $(r=-0.123$, $p=0.015)$. While there was a poor negative correlation between right $\mathrm{VMO}$ tone and age $(r=-0.154, p=0.002)$, VMO elasticity showed a poor positive correlation with age $(r=0.169$, $p=0.001$ ). A poor positive correlation was established between right-left VMO elasticity and age $(r=0.169, p=0.001$; $r=0.208, p=0.001$, respectively). A poor positive correlation was noticed between right-left RF elasticity and age $(r=0.160$, $p=0.002 ; r=0.140, p=0.001$, respectively). Correlations between leg muscle mechanical properties and age are presented in Table 8.

\section{Discussion}

The present study was conducted to establish normative data for stiffness, tone, and elasticity of the lower extremity muscles and to investigate age and sex differences. This study is the first to report mechanical properties of 6 different muscles in both legs. A total of 389 healthy individuals, including 199 females and 190 males, in the age range of 18-50 years were involved in the study. While females were older than males, BMI values were similar between the sexes.

Mechanical properties can be used to define muscle mechanical firmness when skeletal muscles are in a relaxed position and steady-state condition. The RF muscle has been most commonly investigated in previous research. In our study, the mean values of the examined mechanical parameters of the RF muscles were lower in healthy participants than those reported for older adults in previous papers $[6,15]$. A direct comparison of data for other muscles is not possible owing to differences in the experimental design, study population, and age groups.

Our results showed greater muscle tones for right TA, left GM and RF than their counterparts in all participants. The muscle tone can be classified as neural and non-neu- 
Table 6. Comparison of the mechanical properties of lower extremity muscles in males and females

\begin{tabular}{|c|c|c|c|c|c|c|c|c|}
\hline \multirow[b]{2}{*}{ Parameter } & \multicolumn{4}{|c|}{ Males $(n=190)$} & \multicolumn{4}{|c|}{ Females $(n=199)$} \\
\hline & $\begin{array}{c}\text { Right } \\
(\text { mean } \pm S D)\end{array}$ & $\begin{array}{c}\text { Left } \\
(\text { mean } \pm S D)\end{array}$ & $z$ & $p$ & $\begin{array}{c}\text { Right } \\
(\text { mean } \pm S D)\end{array}$ & $\begin{array}{c}\text { Left } \\
(\text { mean } \pm S D)\end{array}$ & $z$ & $p$ \\
\hline TA tone $(\mathrm{Hz})$ & $20.95 \pm 2.66$ & $20.63 \pm 2.65$ & -1.656 & 0.098 & $16.16 \pm 2.1$ & $16.02 \pm 2.11$ & -1.543 & 0.123 \\
\hline TA stiffness $(\mathrm{N} / \mathrm{m})$ & $405.65 \pm 74.17$ & $403.59 \pm 63.66$ & -0.109 & 0.913 & $326.72 \pm 76.54$ & $319.49 \pm 73.19$ & -2.395 & 0.017 \\
\hline TA elasticity (log) & $1.2 \pm 0.38$ & $1.18 \pm 0.38$ & -0.754 & 0.451 & $1.06 \pm 0.23$ & $1.03 \pm 0.22$ & -2.333 & 0.020 \\
\hline $\mathrm{GL}$ tone $(\mathrm{Hz})$ & $16.18 \pm 1.54$ & $16.34 \pm 1.78$ & -1.556 & 0.12 & $14.53 \pm 1.55$ & $14.58 \pm 1.64$ & -0.941 & 0.347 \\
\hline GL stiffness (N/m) & $279.38 \pm 35.56$ & $290.86 \pm 60.82$ & -3.24 & 0.001 & $256.5 \pm 36.62$ & $258.58 \pm 39.12$ & -1.001 & 0.317 \\
\hline GL elasticity (log) & $1.24 \pm 0.29$ & $1.29 \pm 0.29$ & -2.424 & 0.015 & $1.13 \pm 0.24$ & $1.13 \pm 0.2$ & -0.208 & 0.835 \\
\hline GM tone $(\mathrm{Hz})$ & $16.22 \pm 1.74$ & $16.07 \pm 1.59$ & -1.459 & 0.144 & $14.18 \pm 1.46$ & $14.03 \pm 1.6$ & -2.172 & 0.030 \\
\hline GM stiffness (N/m) & $269.05 \pm 33.85$ & $269.46 \pm 34.2$ & -0.498 & 0.619 & $244.11 \pm 32.78$ & $239.7 \pm 33.78$ & -2.065 & 0.039 \\
\hline GM elasticity (log) & $1.41 \pm 0.3$ & $1.39 \pm 0.32$ & -0.466 & 0.641 & $1.24 \pm 0.24$ & $1.22 \pm 0.26$ & -1.76 & 0.078 \\
\hline VL tone $(\mathrm{Hz})$ & $16.94 \pm 2.01$ & $16.87 \pm 2$ & -0.375 & 0.707 & $13.33 \pm 1.91$ & $13.25 \pm 1.89$ & -0.817 & 0.414 \\
\hline VL stiffness $(\mathrm{N} / \mathrm{m})$ & $298.66 \pm 47.58$ & $297.52 \pm 46.69$ & -0.206 & 0.837 & $223.29 \pm 49.15$ & $220.61 \pm 50.59$ & -1.058 & 0.290 \\
\hline VL elasticity (log) & $1.43 \pm 0.32$ & $1.36 \pm 0.3$ & -3.17 & 0.002 & $1.08 \pm 0.27$ & $1.06 \pm 0.29$ & -1.076 & 0.282 \\
\hline VMO tone $(\mathrm{Hz})$ & $13.86 \pm 1.58$ & $14.37 \pm 2.5$ & -3.244 & 0.001 & $11.93 \pm 1.31$ & $11.83 \pm 1.36$ & -1.506 & 0.132 \\
\hline VMO stiffness $(\mathrm{N} / \mathrm{m})$ & $225.89 \pm 37.6$ & $229.59 \pm 44.4$ & -1.407 & 0.159 & $180.2 \pm 28.42$ & $182.9 \pm 32.49$ & -0.851 & 0.395 \\
\hline VMO elasticity (log) & $1.26 \pm 0.29$ & $1.34 \pm 0.37$ & -2.756 & 0.006 & $1.07 \pm 0.35$ & $1.12 \pm 0.34$ & -2.647 & 0.008 \\
\hline $\mathrm{RF}$ tone $(\mathrm{Hz})$ & $14.83 \pm 1.38$ & $14.91 \pm 1.4$ & -0.892 & 0.372 & $13.42 \pm 1.85$ & $13.65 \pm 1.81$ & -2.765 & 0.006 \\
\hline RF stiffness (N/m) & $252.6 \pm 32.62$ & $255.62 \pm 43$ & -0.547 & 0.584 & $214.93 \pm 39.94$ & $217.37 \pm 40.14$ & -1.276 & 0.202 \\
\hline RF elasticity (log) & $1.28 \pm 0.29$ & $1.25 \pm 0.26$ & -1.268 & 0.205 & $1.04 \pm 0.28$ & $1.02 \pm 0.26$ & -1.551 & 0.121 \\
\hline
\end{tabular}

TA - tibialis anterior, GL - gastrocnemius lateralis, GM - gastrocnemius medialis, VL - vastus lateralis, VMO - vastus medialis obliquus,

$\mathrm{RF}$ - rectus femoris

Bold denotes statistically significant values.

ral at rest. Non-neural aspects involve no neural activation and the muscle tone comprises passive stiffness and viscoelastic properties. Muscle tone is not irreversibly dependent on age but can be modulated by direct muscle contraction, physical exercise, or vigorous sports activities. Athletes have a larger cross-sectional area of muscle than sedentary people [32]. Greater muscle tone as observed in the TA $\mathrm{GM}$, and RF muscles in all participants could be associated with a smaller cross-sectional area or whether these muscles were relaxed in resting position or not [33]. However, we did not directly measure the cross-sectional area of the muscles or used EMG to predict muscular activation in resting position. Elasticity is an indicator of the ability of muscles to return to their original state after contraction or when directly compressed. In the present study, right TA, VL, RF, and left VMO were found to have lower muscle elasticity (the logarithmic decrement was higher). The myotonometric parameters depend on the tissue beneath the measuring point. If measured on the paraspinal muscle medially or laterally, the latter point shows substantially lower values owing to fascia and muscle tissue organization [34]. Significant differences in regional muscles have also been observed [35]. The myofascial fat tissue could be an important factor for our subjects who were sedentary middle-aged adults and the subcutaneous fat tissue was not prominent. Individual differences were also determined in different studies previously [22, 35]. In the present study, intramuscular components were not evaluated at the physiological level. It might be of value to compare the mechanical properties of the muscles in this aspect in future studies.
Clinicians often assess the contralateral side to determine abnormalities of the injured side. This approach is useful in conditions that cause muscle atrophy or imbalance. Accurate assessment and management of musculoskeletal problems are central to rehabilitation and monitoring treatment efficacy. Muscles of the dominant leg (which is the right leg for the majority) are usually found to be stronger than those of the other leg in the general population. In this study, the right leg was dominant in $91 \%$ of the participants and the left leg in $9 \%$. It should not be assumed that the mechanical properties of a muscle will affect the muscle strength in the same way as leg dominance will affect the muscle strength. Comparing the right and left extremities of all individuals revealed that the magnitude of difference between both extremities was less than approximately $5 \%$. According to Gapayeva and Vain [36], up to $5 \%$ of the difference between the extremities can be accepted as normal; however, further follow-up is recommended if the difference is $5-10 \%$, and for the differences above $10 \%$, the test should be repeated. Our results showed no significant difference in all mechanical parameters between the dominant and non-dominant legs. Three studies investigated differences in leg dominance using the Myoton device and revealed no significant difference between the dominant and non-dominant side [15, 22, 37]. The result of these studies support our findings.

Comparing the mechanical properties of the muscles by sex showed that bilateral muscle tone, stiffness, and elasticity were greater in males than in females. Stiffness, tone (nonneural form), and elasticity are dependent on the muscle structure (length and cross-sectional area) and the intrinsic 
Table 7. Comparison of the mechanical properties of lower extremity muscles depending on age

\begin{tabular}{|c|c|c|c|c|c|}
\hline \multirow[b]{2}{*}{ Parameter } & \multicolumn{3}{|c|}{ Age groups } & \multirow[b]{2}{*}{$\chi^{2}$} & \multirow[b]{2}{*}{$p$} \\
\hline & $\begin{array}{l}\text { Group } 1(n=235) \\
\quad(\text { mean } \pm S D)\end{array}$ & $\begin{array}{l}\text { Group } 2(n=85) \\
\quad(\text { mean } \pm S D)\end{array}$ & $\begin{array}{l}\text { Group } 3(n=69) \\
\quad(\text { mean } \pm S D)\end{array}$ & & \\
\hline Right TA tone $(\mathrm{Hz})$ & $18.91 \pm 3.35^{a}$ & $17.46 \pm 3.32$ & $18.43 \pm 3.33$ & 12.224 & 0.002 \\
\hline Right TA stiffness (N/m) & $376.11 \pm 85.25^{a}$ & $342.88 \pm 89.24$ & $355.94 \pm 72.68$ & 12.789 & 0.002 \\
\hline Right TA elasticity (log) & $1.11 \pm 0.31$ & $1.07 \pm 0.3$ & $1.25 \pm 0.35^{\mathrm{b}, \mathrm{c}}$ & 15.941 & 0.001 \\
\hline Left TA tone $(\mathrm{Hz})$ & $18.53 \pm 3.3^{a}$ & $17.4 \pm 3.29$ & $18.45 \pm 3.29$ & 7.398 & 0.025 \\
\hline Left TA stiffness (N/m) & $368.75 \pm 79.25^{a}$ & $341.96 \pm 89.17$ & $355.62 \pm 69.63$ & 7.572 & 0.023 \\
\hline Left TA elasticity (log) & $1.1 \pm 0.32$ & $1.03 \pm 0.25$ & $1.22 \pm 0.35^{\mathrm{b}, \mathrm{c}}$ & 14.755 & 0.001 \\
\hline Right GL tone $(\mathrm{Hz})$ & $15.43 \pm 1.69$ & $15.11 \pm 1.95$ & $15.29 \pm 1.68$ & 2.541 & 0.281 \\
\hline Right GL stiffness (N/m) & $266.57 \pm 38.37$ & $265.2 \pm 38.86$ & $274.51 \pm 34.31$ & 3.960 & 0.138 \\
\hline Right GL elasticity (log) & $1.15 \pm 0.26$ & $1.17 \pm 0.27$ & $1.31 \pm 0.26^{\mathrm{b}, \mathrm{c}}$ & 20.309 & 0.001 \\
\hline Left $\mathrm{GL}$ tone $(\mathrm{Hz})$ & $15.46 \pm 1.88$ & $15.4 \pm 2.08$ & $15.45 \pm 1.87$ & 0.229 & 0.892 \\
\hline Left GL stiffness (N/m) & $272.37 \pm 43.6$ & $269.08 \pm 43.03$ & $287.58 \pm 84.69$ & 3.602 & 0.165 \\
\hline Left GL elasticity (log) & $1.18 \pm 0.27$ & $1.2 \pm 0.22$ & $1.32 \pm 0.25^{\mathrm{b}, \mathrm{c}}$ & 19.284 & 0.001 \\
\hline Right GM tone $(\mathrm{Hz})$ & $15.24 \pm 1.88$ & $14.97 \pm 1.86$ & $15.21 \pm 2$ & 1.424 & 0.491 \\
\hline Right GM stiffness (N/m) & $253.94 \pm 36.02$ & $257.06 \pm 35.93$ & $263.35 \pm 32.75^{\mathrm{c}}$ & 6.299 & 0.043 \\
\hline Right GM elasticity (log) & $1.29 \pm 0.29$ & $1.31 \pm 0.22$ & $1.45 \pm 0.32^{\mathrm{b}, \mathrm{c}}$ & 14.080 & 0.001 \\
\hline Left GM tone (Hz) & $15.02 \pm 1.91$ & $15 \pm 2$ & $15.07 \pm 1.7$ & 0.331 & 0.847 \\
\hline Left GM stiffness (N/m) & $252.2 \pm 39.05$ & $255.95 \pm 36.99$ & $259.04 \pm 29.34$ & 3.408 & 0.182 \\
\hline Left GM elasticity (log) & $1.28 \pm 0.3$ & $1.28 \pm 0.27$ & $1.42 \pm 0.33^{\mathrm{b}, \mathrm{c}}$ & 10.617 & 0.005 \\
\hline Right VL tone $(\mathrm{Hz})$ & $15.34 \pm 2.6^{a}$ & $14.53 \pm 2.72$ & $14.98 \pm 2.74$ & 7.093 & 0.029 \\
\hline Right VL stiffness (N/m) & $260.73 \pm 59.18$ & $255.53 \pm 62.93$ & $263.59 \pm 66.79$ & 1.020 & 0.601 \\
\hline Right VL elasticity (log) & $1.23 \pm 0.34$ & $1.22 \pm 0.29$ & $1.33 \pm 0.41$ & 2.926 & 0.231 \\
\hline Left VL tone $(\mathrm{Hz})$ & $15.21 \pm 2.54^{a}$ & $14.37 \pm 2.66$ & $15.15 \pm 2.93$ & 8.415 & 0.015 \\
\hline Left VL stiffness $(\mathrm{N} / \mathrm{m})$ & $260.64 \pm 59.96$ & $247.55 \pm 61.92$ & $262.86 \pm 68.39$ & 5.922 & 0.052 \\
\hline Left VL elasticity (log) & $1.2 \pm 0.33$ & $1.17 \pm 0.28$ & $1.3 \pm 0.37$ & 4.464 & 0.107 \\
\hline Right VMO tone $(\mathrm{Hz})$ & $13.07 \pm 1.72^{\mathrm{a}}$ & $12.5 \pm 1.7$ & $12.68 \pm 1.77$ & 10.064 & 0.007 \\
\hline Right VMO stiffness $(\mathrm{N} / \mathrm{m})$ & $200.28 \pm 42.83$ & $199.49 \pm 35.81$ & $213.84 \pm 34.81^{\mathrm{b}, \mathrm{c}}$ & 8.705 & 0.013 \\
\hline Right VMO elasticity (log) & $1.11 \pm 0.29$ & $1.16 \pm 0.33$ & $1.35 \pm 0.41^{\mathrm{b}, \mathrm{c}}$ & 17.333 & 0.001 \\
\hline Left VMO tone $(\mathrm{Hz})$ & $13.28 \pm 2.45^{a}$ & $12.59 \pm 2.41$ & $12.96 \pm 1.95$ & 9.355 & 0.009 \\
\hline Left VMO stiffness (N/m) & $203.02 \pm 45.3$ & $205.32 \pm 48.34$ & $215.35 \pm 40.04$ & 5.601 & 0.061 \\
\hline Left VMO elasticity (log) & $1.17 \pm 0.34^{\mathrm{a}}$ & $1.28 \pm 0.44$ & $1.35 \pm 0.37^{b}$ & 14.741 & 0.001 \\
\hline Right RF tone (Hz) & $14.19 \pm 1.63$ & $13.8 \pm 1.95$ & $14.23 \pm 2.01$ & 4.266 & 0.118 \\
\hline Right RF stiffness (N/m) & $230.87 \pm 41.17$ & $232.93 \pm 43.94$ & $242.2 \pm 36.24$ & 2.770 & 0.250 \\
\hline Right RF elasticity (log) & $1.11 \pm 0.28$ & $1.17 \pm 0.28$ & $1.3 \pm 0.37^{c}$ & 14.855 & 0.001 \\
\hline Left RF tone $(\mathrm{Hz})$ & $14.38 \pm 1.65^{\mathrm{a}}$ & $13.82 \pm 1.78$ & $14.42 \pm 1.94^{\mathrm{c}}$ & 8.954 & 0.011 \\
\hline Left RF stiffness $(\mathrm{N} / \mathrm{m})$ & $236.47 \pm 49.13$ & $226.62 \pm 39.63$ & $246.25 \pm 38.2^{c}$ & 7.768 & 0.021 \\
\hline Left RF elasticity (log) & $1.1 \pm 0.27$ & $1.13 \pm 0.26$ & $1.24 \pm 0.32^{\mathrm{b}, \mathrm{c}}$ & 10.311 & 0.006 \\
\hline
\end{tabular}

TA - tibialis anterior, GL - gastrocnemius lateralis, GM - gastrocnemius medialis, VL - vastus lateralis, VMO - vastus medialis obliquus, $\mathrm{RF}$ - rectus femoris

Significant difference after Kruskal-Wallis test results and post-hoc pairwise (Dunn correction) comparisons output of Kruskal-Wallis test. Bold denotes statistically significant values.

a $p<0.05$, group 1 vs. group 2

${ }^{\mathrm{b}} p<0.05$, group 1 vs. group 3

${ }^{c} p<0.05$, group 2 vs. group 3 
Table 8. Correlations between age and leg muscle mechanical properties

\begin{tabular}{|c|c|c|c|c|c|c|}
\hline \multicolumn{4}{|c|}{ Right } & \multicolumn{3}{|c|}{ Left } \\
\hline & TA tone $(\mathrm{Hz})$ & TA stiffness (N/m) & TA elasticity (log) & TA tone $(\mathrm{Hz})$ & TA stiffness (N/m) & TA elasticity (log) \\
\hline$r$ & $-0.103^{*}$ & $-0.125^{\star}$ & 0.088 & -0.074 & $-0.115^{\star}$ & 0.053 \\
\hline & $\mathrm{GL}$ tone $(\mathrm{Hz})$ & GL stiffness (N/m) & GL elasticity (log) & $\mathrm{GL}$ tone $(\mathrm{Hz})$ & GL stiffness (N/m) & GL elasticity (log) \\
\hline$r$ & -0.081 & 0.060 & $0.229^{\star *}$ & -0.015 & 0.044 & $0.194^{\star *}$ \\
\hline & GM tone $(\mathrm{Hz})$ & GM stiffness $(\mathrm{N} / \mathrm{m})$ & GM elasticity (log) & $\mathrm{GM}$ tone $(\mathrm{Hz})$ & GM stiffness $(\mathrm{N} / \mathrm{m})$ & GM elasticity (log) \\
\hline$r$ & -0.036 & 0.084 & $0.157^{\star *}$ & -0.031 & 0.061 & $0.133^{\star *}$ \\
\hline & VL tone $(\mathrm{Hz})$ & VL stiffness (N/m) & VL elasticity (log) & VL tone $(\mathrm{Hz})$ & VL stiffness (N/m) & VL elasticity (log) \\
\hline$r$ & $-0.123^{*}$ & -0.033 & 0.037 & -0.090 & -0.077 & 0.039 \\
\hline & VMO tone $(\mathrm{Hz})$ & VMO stiffness $(\mathrm{N} / \mathrm{m})$ & VMO elasticity (log) & VMO tone $(\mathrm{Hz})$ & VMO stiffness $(\mathrm{N} / \mathrm{m})$ & VMO elasticity (log) \\
\hline$r$ & $-0.154^{\star *}$ & 0.064 & $0.169^{* \star}$ & $-0.110^{*}$ & 0.079 & $0.208^{\star *}$ \\
\hline & RF tone $(\mathrm{Hz})$ & RF stiffness (N/m) & RF elasticity (log) & $\mathrm{RF}$ tone $(\mathrm{Hz})$ & RF stiffness (N/m) & RF elasticity (log) \\
\hline$r$ & -0.034 & 0.070 & $0.160^{\star *}$ & -0.051 & 0.023 & $0.140^{* *}$ \\
\hline
\end{tabular}

$r$ - Spearman rank correlation coefficient, TA - tibialis anterior, GL - gastrocnemius lateralis, GM - gastrocnemius medialis,

$\mathrm{VL}$ - vastus lateralis, $\mathrm{VMO}$ - vastus medialis obliquus, $\mathrm{RF}$ - rectus femoris

* significant difference at the level of $0.05,{ }^{* *}$ significant difference at the level of 0.01

composition of the muscle [38, 39]. The reasons for higher mechanical properties might be greater strength and muscle mass, lower fat content, different muscle fibre characteristics and cross-sectional area in males [40-45]. This could be related to the fact that females have a higher total body fat and lower muscle mass than males [46, 47], but we did not investigate anthropometric characteristics; however, males and females had comparable BMI. Differences in the muscle mass, increased myofascial content, and altered body fat distribution cannot be explained solely by the BMI [48]. Previous studies, using different measurement devices, indicated that BMI was an additional factor that did not affect the biomechanical muscle parameters [27, 49]. On the other hand, one study suggested that the variance in the stiffness $(7.5 \%)$ and elasticity (4\%) of the upper trapezius muscle as assessed by MyotonPRO could be attributed to BMI. In this regard, the use of a basic BMI calculated from height and body weight may not be an appropriate method for myotonometric assessments. Agyapong-Badu et al. [6] implied that there was an inverse relationship between muscle tone and subcutaneous adipose tissue in sedentary participants; a thicker subcutaneous fat layer can alter muscle response, decrease oscillations and frequencies, and therefore reduce muscle tone. Thus, other body composition measures, such as subcutaneous fat thickness, lean body mass, and fat mass index, could be investigated in future studies to explain changes in muscle mechanical properties.

Males and females showed diverse viscoelastic characteristics in different muscles and legs. Intragroup differences in males and females might have resulted from differences in activities of daily living, occupations [50], gait patterns [51], neuromuscular strategies [52], and physical activity levels [30] of the participants. The activities of daily living and job tasks are associated with repeated movements and static loading for maintaining posture. These activities include both static and dynamic movements that can cause a variety of musculoskeletal alignments or neuromuscular strategies. Also, the working position depends partly on the requirements of the surrounding factors and partly on other requirements, such as using force, personal fitness level, command of specific movement skills, as well as the ability to relax between work operations. Two studies with Myoton-3 found that muscle stiffness, tone, and elasticity might change depending on occupational variation in healthy individuals $[50,53]$.

Comparing mechanical properties between the age groups revealed that bilateral muscle tone and stiffness of TA, muscle tone of $\mathrm{VMO}$ and $\mathrm{VL}$, and left RF tone were greater in the younger groups. We believe that some factors, such as physical activity, activities of daily living, or soft tissue infiltration, might explain these results. Myofascial tissue can change dynamically in response to external and internal loads [54]. Kim et al. [55] reported that greater muscle tone indicated increased exercise load or pain. Hence, muscle tone can be modulated by physical activity. We suggest that the bilaterally greater level of muscle tone in the younger group might be related to their level of physical activity.

The elasticity of the bilateral TA, GM, GL, VMO, and RF muscles decreased with advancing age. This finding is in accordance with the results of a previous study, in which mechanical properties of the upper trapezius and sternocleidomastoid muscles were examined in relation to the sitting or lying position, and it was reported that aging decreased only the flexibility of upper trapezius [49]. Aging has more prominent effects (increased stiffness and decreased elasticity) on the mechanical properties of the lower extremity muscles than those of the upper extremity [56]. Ultrasound imaging has indicated that the non-contractile components of the VL muscle, which is a part of the quadriceps, are more numerous than those of the supraspinatus muscle [57]. Along with aging, the increase in fibrous components and the decrease in size and number of muscle fibres lead to a decrease in the contractile elements [58]. In a study by Kent-Braun et al. [59], older adults were shown to have smaller contractile areas compared with young adults. In our study, it is quite likely that the prominent difference in elasticity can be a result of the increase in non-contractile components. In a study comparing athletes and sedentary individuals, the fact that the former presented lower elasticity than the latter was attributed to the effect of physical activity on muscle flexibility during rest [30]. We suggest that lower levels of elasticity in the elder group than in other groups might be explained by their decreased level of physical activity. 
Our results showed that age had a positive poor correlation with TA stiffness and VMO tone bilaterally, and a negative poor correlation with GL, GM, VMO, and RF elasticity bilaterally. Previous studies demonstrated higher stiffness and lower elasticity in lower and upper extremity muscles and face muscles in older individuals vs. younger people [6, 30, 49,60]. Therefore, the muscles that were investigated in these studies were differently affected by age, which is consistent with our results. Gervasi et al. [30] tested two muscles from the dominant side (rectus femoris and biceps brachii) and found that age had a slight effect on the tone of females' biceps brachii but moderate effect on the stiffness and elasticity of both muscles. A poor correlation was demonstrated for stiffness and elasticity of both muscles in their male group, but not for the tone [30]. Agyapong-Badu et al. [6] observed that the muscle tone and stiffness were positively and elasticity was negatively correlated with age in the case of biceps brachii, with the same results for rectus femoris except for the age correlation with the tone. Kocur et al. [49] demonstrated that the stiffness and elasticity of the neck muscles were positively correlated with age, which accounted for their findings in the sternocleidomastoid muscle (stiffness: $28.4 \%$, elasticity: $53 \%$ ) and the upper trapezius muscle (stiffness: $22 \%$, elasticity: $13 \%$ ).

The major finding of our study was that age constituted the major correlate of the elasticity of specific lower extremity muscles, TA stiffness, and VMO tone. The higher stiffness and tone and lower elasticity in humans have previously been demonstrated to increase the risk for soft tissue and bone injuries [61-63]. From a practical viewpoint, increased TA stiffness and VMO tone can potentially lead to increased risk of falls because these muscles are important for gait and daily activities. Also, decreased muscle elasticity and higher stiffness may adversely affect the quality of muscle contractions and postural control [64, 65], impair blood circulation, and cause premature fatigue $[34,66]$. Further studies are warranted to compare myotonic measurements with laboratorybased objective methods in order to postulate an accurate interpretation of findings regarding muscle physiology.

\section{Limitations}

Our study provides information that may be important for assessing the mechanical properties of the musculoskeletal system. A number of limitations have hindered our ability to draw definitive conclusions. First, we used only a classic BMI calculated from height and weight, and did not evaluate the adipose tissue of the participants. The subjects may have had a different body composition, which can affect the interpretation of our results. The second limitation is that the present study did not include older age groups (50-65 or over 65 years). If these groups had been involved, we could have better investigated the progressive effects of aging and additional data could have been presented for the reduced muscle elasticity and increased muscle stiffness and tone. The findings of the present study may provide an opportunity to establish normative values for the mechanical properties of different muscles in various populations and to form the basis for further research.

\section{Conclusions}

The measured mechanical properties of the lower extremity muscles were bilaterally higher in males than females in all parameters. These mechanical properties showed different characteristics in different muscles for both sexes. Leg domi- which were found comparable between the two sides. The elasticity of GL, GM, VMO, RF decreased, and TA stiffness and VMO tone increased with advancing age in both legs. We believe that increased muscle stiffness and reduced muscle elasticity with advancing age may adversely affect mobility, cause premature early fatigue, or impair blood circulation. The study presents data on altered mechanical properties of leg muscles in relation to sex, leg dominance, and age. These findings can provide important information for future studies involving different populations or disorders.

\section{Acknowledgements}

The authors would like to thank all individuals who participated in this study.

\section{Disclosure statement}

No author has any financial interest or received any financial benefit from this research.

\section{Conflict of interest}

The authors state no conflict of interest.

\section{References}

1. Kragstrup TW, Kjaer M, Mackey A. Structural, biochemical, cellular, and functional changes in skeletal muscle extracellular matrix with aging. Scand J Med Sci Sports. 2011;21(6):749-757; doi: 10.1111/j.1600-0838.2011. 01377.x.

2. Trappe T. Influence of aging and long-term unloading on the structure and function of human skeletal muscle. Appl Physiol Nutr Metab. 2009;34(3):459-464; doi: 10.1139/ H09-041.

3. Haus JM, Carrithers JA, Trappe SW, Trappe TA. Collagen, cross-linking, and advanced glycation end products in aging human skeletal muscle. J Appl Physiol. 2007; 103(6):2068-2076; doi: 10.1152/japplphysiol.00670.2007.

4. Barros EM, Rodrigues CJ, Rodrigues NR, Oliveira RP, Barros TE, Rodrigues Jr AJ. Aging of the elastic and collagen fibers in the human cervical interspinous ligaments. Spine J. 2002;2(1):57-62; doi: 10.1016/S1529-9430(01) 00167-X.

5. Piasecki M, Ireland A, Jones DA, McPhee JS. Age-dependent motor unit remodelling in human limb muscles. Biogerontology. 2016;17(3):485-496; doi: 10.1007/s10522 -015-9627-3.

6. Agyapong-Badu S, Warner M, Samuel D, Stokes M. Measurement of ageing effects on muscle tone and mechanical properties of rectus femoris and biceps brachii in healthy males and females using a novel hand-held myometric device. Arch Gerontol Geriatr. 2016;62:59-67; doi: 10.1016/j.archger.2015.09.011.

7. Pullman SL, Goodin DS, Marquinez Al, Tabbal S, Rubin M. Clinical utility of surface EMG: report of the therapeutics and technology assessment subcommittee of the American Academy of Neurology. Neurology. 2000; 55(2):171-177; doi: 10.1212/WNL.55.2.171.

8. Menkes DL, Pierce R. Needle EMG muscle identification: a systematic approach to needle EMG examination. Clin Neurophysiol Pract. 2019;4:199-211; doi: 10.1016/ j.cnp.2019.08.003.

9. Feng YN, Li YP, Liu CL, Zhang ZJ. Assessing the elastic properties of skeletal muscle and tendon using shearwave ultrasound elastography and MyotonPRO. Sci Rep. 2018;8(1):17064; doi: 10.1038/s41598-018-34719-7.

10. Correa-de-Araujo R, Harris-Love MO, Miljkovic I, Fragala MS, Anthony BW, Manini TM. The need for standard- 
ized assessment of muscle quality in skeletal muscle function deficit and other aging-related muscle dysfunctions: a symposium report. Front Physiol. 2017;8:87; doi: 10.3389/fphys.2017.00087.

11. Bailey L, Samuel D, Warner MB, Stokes M. Parameters representing muscle tone, elasticity and stiffness of biceps brachii in healthy older males: symmetry and withinsession reliability using the MyotonPRO. J Neurol Disord. 2013;1(1):116; doi: 10.4172/jnd.1000116.

12. Myoton. Available from: https://www.myoton.com/technology/ [2016].

13. Zinder SM, Padua DA. Reliability, validity, and precision of a handheld myometer for assessing in vivo muscle stiffness. J Sport Rehabil. 2011;20(3):2010_0051; doi: 10.1123/jsr.2010-0051.

14. Kisilewicz A, Janusiak M, Szafraniec R, Smoter M, Ciszek $B$, Madeleine $P$, et al. Changes in muscle stiffness of the trapezius muscle after application of ischemic compression into myofascial trigger points in professional basketball players. J Hum Kinet. 2018;64(1):35-45; doi: 10.2478/hukin-2018-0043.

15. Aird L, Samuel D, Stokes M. Quadriceps muscle tone, elasticity and stiffness in older males: reliability and symmetry using the MyotonPRO. Arch Gerontol Geriatr. 2012; 55(2):31-39; doi: 10.1016/j.archger.2012.03.005.

16. Fröhlich-Zwahlen AK, Casartelli NC, Item-Glatthorn JF, Maffiuletti NA. Validity of resting myotonometric assessment of lower extremity muscles in chronic stroke patients with limited hypertonia: a preliminary study. J Electromyogr Kinesiol. 2014;24(5):762-769; doi: 10.1016/j. jelekin.2014.06.007.

17. Lo WLA, Zhao JL, Li L, Mao YR, Huang DF. Relative and absolute interrater reliabilities of a hand-held myotonometer to quantify mechanical muscle properties in patients with acute stroke in an inpatient ward. Biomed Res Int. 2017;2017:4294028; doi: 10.1155/2017/4294028.

18. An SY, Yeo SM, Cheong IY, Hwang JH. Mechanical properties of muscles around the shoulder in breast cancer patients: intra-rater and inter-rater reliability of the MyotonPRO. PM R. 2020;12(4):374-381; doi: 10.1002/pmrj. 12227.

19. Marusiak J, Jaskólska A, Budrewicz S, Koszewicz M, Jaskólski A. Increased muscle belly and tendon stiffness in patients with Parkinson's disease, as measured by myotonometry. Mov Disord. 2011;26(11):2119-2122; doi: 10.1002/mds.23841.

20. Liu CL, Li YP, Wang XQ, Zhang ZJ. Quantifying the stiffness of Achilles tendon: intra- and inter-operator reliability and the effect of ankle joint motion. Med Sci Monit. 2018; 24:4876-4881; doi: 10.12659/MSM.909531.

21. Schneebeli A, Falla D, Clijsen R, Barbero M. Myotonometry for the evaluation of Achilles tendon mechanical properties: a reliability and construct validity study. BMJ Open Sport Exerc Med. 2020;6(1):e000726; doi: 10.1136/ bmjsem-2019-000726.

22. Viir R, Laiho K, Kramarenko J, Mikkelsson M. Repeatability of trapezius muscle tone assessment by a myometric method. J Mech Med Biol. 2006;6(2):215-228; doi: 10.1142/S0219519406001856.

23. Wang JS, Um GM, Choi JH. Immediate effects of kinematic taping on lower extremity muscle tone and stiffness in flexible flat feet. J Phys Ther Sci. 2016;28(4):1339-1342; doi: 10.1589/jpts.28.1339.

24. Gordon CM, Andrasik F, Schleip R, Birbaumer N, Rea M. Myofascial triggerpoint release (MTR) for treating chronic shoulder pain: a novel approach. J Bodyw Mov Ther. 2016;20(3):614-622; doi: 10.1016/j.jbmt.2016.01.009.

25. Ortega-Cebrian S, Luchini N, Whiteley R. Dry needling: effects on activation and passive mechanical properties of the quadriceps, pain and range during late stage rehabilitation of $A C L$ reconstructed patients. Phys Ther Sport. 2016;21:57-62; doi: 10.1016/j.ptsp.2016.02.001.

26. Usgu S, Yakut Y, Çınar MA. The comparison of Achilles tendon viscoelastic properties in elite runners and soccer players [In Turkish]. Turk J Sports Med. 2020;55; doi: 10.5152/tjsm.2020.185

27. Eby SF, Cloud BA, Brandenburg JE, Giambini H, Song P, Chen S, et al. Shear wave elastography of passive skeletal muscle stiffness: influences of sex and age throughout adulthood. Clin Biomech. 2015;30(1):22-27; doi: 10.1016/ j.clinbiomech.2014.11.011.

28. Domire ZJ, McCullough MB, Chen Q, An KN. Feasibility of using magnetic resonance elastography to study the effect of aging on shear modulus of skeletal muscle. J Appl Biomech. 2009;25(1):93-97; doi: 10.1123/jab.25.1.93.

29. Machin D, Tan SB, Tan SH. Confidence interval for a single mean. Sample size tables for clinical studies. Chichester: Wiley-Blackwell; 2009.

30. Gervasi M, Sisti D, Amatori S, Andreazza M, Benelli P, Sestili $P$, et al. Muscular viscoelastic characteristics of athletes participating in the European Master Indoor Athletics Championship. Eur J Appl Physiol. 2017;117(8): 1739-1746; doi: 10.1007/s00421-017-3668-z.

31. Domholdt E. Physical therapy research. Principles and applications. St. Louis: Saunders; 1993.

32. Ryu M, Jo J, Lee Y, Chung YS, Kim KM, Baek WC. Association of physical activity with sarcopenia and sarcopenic obesity in community-dwelling older adults: the Fourth Korea National Health and Nutrition Examination Survey. Age Ageing. 2013;42(6):734-740; doi: 10.1093/ ageing/aft063.

33. Agyapong-Badu S, Warner M, Samuel D, Stokes M. Practical considerations for standardized recording of muscle mechanical properties using a myometric device: recording site, muscle length, state of contraction and prior activity. J Musculoskelet Res. 2018;21(2):1850010; doi: 10.1142/S0218957718500100.

34. Veraksitš A, Gavronski G, Oha K, Vasar E, Blottner D, Viir R. Mechanical properties of the lumbar muscles regarded to G-Vector. 63rd International Astronautical Congress 2012, Space Life Sciences Symposium (A1). Human Physiology in Space (2).

35. Gavronski G, Veraksitš A, Vasar E, Maaroos J. Evaluation of viscoelastic parameters of the skeletal muscles in junior triathletes. Physiol Meas. 2007;28(6):625-637; doi: 10.1088/0967-3334/28/6/002.

36. Gapeyeva $H$, Vain A. Methodical guide: principles of applying Myoton in physical medicine and rehabilitation. Tartu: Müomeetria; 2008.

37. Mooney K, Warner M, Stokes M. Symmetry and withinsession reliability of mechanical properties of biceps brachii muscles in healthy young adult males using the MyotonPRO device. Work Pap Health Sci. 2013;1(3):1-11.

38. Baumgart E. Stiffness - an unknown world of mechanical science? Injury. 2000;31(2):14-23; doi: 10.1016/ S0020-1383(00)80040-6.

39. Maïsetti O, Hug F, Bouillard K, Nordez A. Characterization of passive elastic properties of the human medial gastrocnemius muscle belly using supersonic shear imaging. J Biomech. 2012;45(6):978-984; doi: 10.1016/j. jbiomech.2012.01.009. 
40. Janssen I, Heymsfield SB, Wang Z, Ross R. Skeletal muscle mass and distribution in 468 men and women aged 18-88 yr. J Appl Physiol. 2000;89(1):81-88; doi: 10.1152/japplphysiol.zdg-1052-corr.2014.

41. Jones EJ, Bishop PA, Woods AK, Green JM. Cross-sectional area and muscular strength. Sports Med. 2008; 38(12):987-994; doi: 10.2165/00007256-20083812000003.

42. Miller AEJ, MacDougall JD, Tarnopolsky MA, Sale DG. Gender differences in strength and muscle fiber characteristics. Europ J Appl Physiol Occup Physiol. 1993;66(3): 254-262; doi: 10.1007/BF00235103.

43. Doherty TJ. The influence of aging and sex on skeletal muscle mass and strength. Curr Opin Clin Nutr. 2001;4(6): 503-508; doi: 10.1097/00075197-200111000-00007.

44. Zamboni M, Zoico E, Scartezzini T, Mazzali G, Tosoni P, Zivelonghi A, et al. Body composition changes in stableweight elderly subjects: the effect of sex. Aging Clin Exp Res. 2003;15(4):321-327; doi: 10.1007/BF03324517.

45. Wüst RC, Morse $\mathrm{Cl}$, de Haan $\mathrm{A}$, Jones DA, Degens $\mathrm{H}$. Sex differences in contractile properties and fatigue resistance of human skeletal muscle. Exp Physiol. 2008; 93(7):843-850; doi: 10.1113/expphysiol.2007.041764.

46. Wells JCK. Sexual dimorphism of body composition. Best Pract Res Clin Endocrinol Metab. 2007;21(3):415430; doi: 10.1016/j.beem.2007.04.007.

47. Karastergiou K, Smith SR, Greenberg AS, Fried SK. Sex differences in human adipose tissues - the biology of pear shape. Biol Sex Differ. 2012;3(1):13; doi: 10.1186/20426410-3-13.

48. Cook Z, Kirk S, Lawrenson S, Sandford S. Use of BMI in the assessment of undernutrition in older subjects: reflecting on practice. Proc Nutr Soc. 2005;64(3):313-317; doi: $10.1079 /$ PNS2005437.

49. Kocur P, Grzeskowiak M, Wiernicka M, Goliwas M, Lewandowski J, Łochyński D. Effects of aging on mechanical properties of sternocleidomastoid and trapezius muscles during transition from lying to sitting position - a cross-sectional study. Arch Gerontol Geriat. 2017; 70:14-18; doi: 10.1016/j.archger.2016.12.005.

50. Ereline J, Pärenson K, Vahtrik D, Pääsuke M, Gapeyeva H. Skeletal muscle tone and motor performance characteristics in dentists as compared to controls. Agron Res. 2017;15(4):1571-1581; doi: 10.15159/ar.17.010.

51. Whittington B, Silder A, Heiderscheit B, Thelen DG. The contribution of passive-elastic mechanisms to lower extremity joint kinetics during human walking. Gait Posture. 2008;27(4):628-634; doi:10.1016/j.gaitpost.2007.08.005.

52. Von Tscharner V, Goepfert B. Gender dependent EMGs of runners resolved by time/frequency and principal pattern analysis. J Electromyogr Kinesiol. 2003;13(3):253272; doi: 10.1016/S1050-6411(02)00111-6.

53. Pille V, Tint P, Hartsenko E. The prevalence of work-related musculoskeletal disorders in computer workers and industrial workers. Med Health Sci J. 2016;17(2):23-30; doi: 10.15208/mhsj.2016.05.

54. Myers TW. Anatomy trains: myofascial meridians for manual and movement therapists. Churchill Livingstone; 2013.

55. Kim DH, Jung YJ, Song, YE, Hwang DH, Ko CY, Kim HS. Measurement of characteristic change using MyotonPRO in low back muscles during a long-term driving; pilot study. Jpn J Ergon. 2015;51(Suppl.):S450-S453; doi: 10.5100/jje.51.S450.

56. Samuel D, Wilson K, Martin HJ, Allen R, Sayer AA, Stokes M. Age-associated changes in hand grip and quadriceps muscle strength ratios in healthy adults. Aging Clin Exp Res. 2012;24(3):245-250; doi: 10.1007/ BF03325252.

57. Nielsen PK, Jensen BR, Darvann T, Jørgensen K, Bakke M. Quantitative ultrasound tissue characterization in shoulder and thigh muscles - a new approach. BMC Musculoskelet Disord. 2006;7(1):2; doi: 10.1186/14712474-7-2.

58. Perkisas S, De Cock A, Verhoeven V, Vandewoude M. Physiological and architectural changes in the ageing muscle and their relation to strength and function in sarcopenia. Eur Geriatr Med. 2016;7(3):201-206; doi: 10.1016/j.eurger.2015.12.016.

59. Kent-Braun JA, Ng AV, Young K. Skeletal muscle contractile and noncontractile components in young and older women and men. J Appl Physiol. 2000;88(2):662668; doi: 10.1152/jappl.2000.88.2.662.

60. Dietsch AM, Clark HM, Steiner JN, Solomon NP. Effects of age, sex, and body position on orofacial muscle tone in healthy adults. J Speech Lang Hear Res. 2015;58(4): 1145-1150; doi: 10.1044/2015_JSLHR-S-14-0325.

61. Butler RJ, Crowell HP, Davis IM. Lower extremity stiffness: implications for performance and injury. Clin Biomech. 2003;18(6):511-517; doi: 10.1016/S0268-0033(03) 00071-8.

62. Lim KT, Choi WJ. Soft tissue stiffness over the hip increases with age and its implication in hip fracture risk in older adults. J Biomech. 2019;93:28-33; doi: 10.1016/j. jbiomech.2019.06.002.

63. Pickering Rodriguez EC, Watsford ML, Bower RG, Murphy AJ. The relationship between lower body stiffness and injury incidence in female netballers. Sports Biomech. 2017;16(3):361-373; doi: 10.1080/14763141. 2017.1319970.

64. Maffiuletti NA, Aagaard P, Blazevich AJ, Folland J, Tillin N, Duchateau J. Rate of force development: physiological and methodological considerations. Eur J Appl Physiol. 2016;116(6):1091-1116; doi: 10.1007/s00421016-3346-6.

65. Paillard T. Effects of general and local fatigue on postural control: a review. Neurosci Biobehav Rev. 2012;36(1): 162-176; doi: 10.1016/j.neubiorev.2011.05.009.

66. Cheng AJ, Davidson AW, Rice CL. The influence of muscle length on the fatigue-related reduction in joint range of motion of the human dorsiflexors. Eur J Appl Physiol. 2010;109(3):405-415; doi: 10.1007/s00421-010-1364-3. 